\title{
Delayed Presentation of a Penile Fracture: A Case Report
}

\author{
- Ashok Kumar Yadav ${ }^{1} \bullet$ Sudhir Kumar Singh ${ }^{2} \bullet$ Raju Chapagain $^{1} \bullet$ Prem Das $^{1} \bullet$ Jag Mohan Osti ${ }^{1} \bullet$ Durga Neupane $^{1}$ \\ Submitted 19 January 2021 \\ $\quad$ Ashok Kumar Yadav \\ dr_yadavashok@yahoo.com \\ iD https://orcid.org/0000-0002-9254-0463 \\ ${ }^{1}$ Department of General Practice \& \\ Emergency Medicine \\ ${ }^{2}$ Urology Division, Department of \\ Surgery, B. P. Koirala Institute of Health \\ Sciences, Dharan. \\ Accepted 25 April 2021 \\ Published 30 June 2021 \\ Penile fracture is a urological emergency caused by blunt trauma \\ to an erect penis. We report a case of a 40 -year-old male who \\ presented with a complaint of a painful swelling of the penis \\ for 4 days. On examination, a flaccid swollen tender penis with \\ bluish discoloration over the shaft and scrotum was noted. A \\ clinical diagnosis of delayed penile fracture was made which was \\ managed immediately surgically under spinal anesthesia. Our \\ report emphasizes that penile fracture is diagnosed solely on \\ a reliable history and clinical examination. It has outstanding \\ outcome despite delayed presentation if treated promptly.
}

\section{Citation}

"Yadav AK, Singh SK, Chapagain R, Das P, Osti JM, Neupane D. Delayed presentation of a penile fracture: $A$ case report. JBPKIHS. 2021;4(1):56-58.

doi https://doi.org/10.3126/jbpkihs.v4i1.36948

\section{(c) (i) $\circledast \Theta$}

This work is licensed under a Creative Commons Attribution NonCommercial 4.0 International License.
Keywords: Penile fracture, Surgical repair, Trauma

\section{Declarations}

Ethics approval and consent to participate: Not applicable Consent for publication: Obtained from the patient.

Availability of data and materials: The datasets used and/or analyzed during the current study are available from the corresponding author on reasonable request. All relevant data are within the manuscript.

Competing interest: None

Funding: None

Authors' contributions: AKY: concepts, design, manuscript preparation and review. SKS: literature search, manuscript editing RC: literature search, manuscript preparation. PD: manuscript editing. JMO: manuscript review and editing. DN: literature search, manuscript review. All authors have read and approved the final manuscript.
Acknowledgement: None 
$\mathrm{P}$ enile fracture is a surgical emergency. It results from an injury to an erect penis. It is usually unilateral, transverse, 1 to $2 \mathrm{~cm}$ in length, and distal to the suspensory ligament [1]. Diagnosis is purely clinical, based on a history of trauma associated with a cracking sound, pain and immediate detumescence, and a typical egg-plant deformity of penis on bedside examination [2]. We report a case of delayed presentation, which was successfully managed with surgery.

\section{CASE}

40-year-old male presented to the emergency unit $\mathrm{A}_{\text {with complain of painful swelling of the penis for } 4}$ days which had occurred during self, forceful bending of the penile shaft in erected state. There was a sudden pop sound associated with sharp penile pain, immediate detumescence, and absence of erection. A swelling and subsequent bruising of the penoscrotal region followed then after. There was no history of aggressive intercourse and masturbation, hematuria, or voiding difficulties. The patient was referred to our center as no improvement was observed after conservative management at a local hospital. On examination, a flaccid, swollen tender penis with bluish discoloration over the shaft of the penis and scrotum was noticed (Fig. 1). No blood was present over the meatus. The clinical diagnosis of a delayed presentation of penile fracture was made. An immediate surgical repair was performed under spinal anesthesia.

The surgical access was obtained through a distal

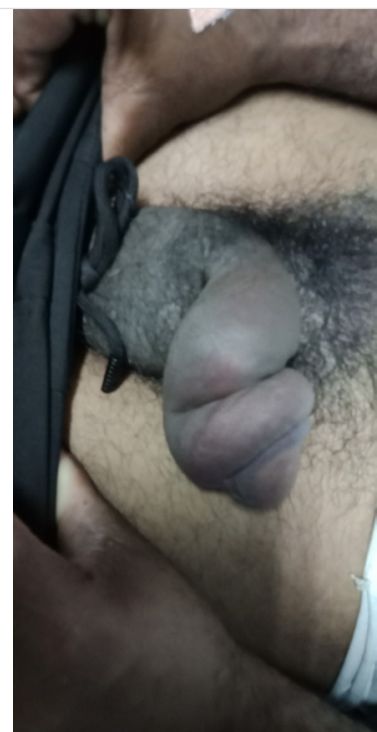

Figure 1: Typical penile deformity (swollen, flaccid, and discolored penis) circumferential degloving incision. Around $2 \mathrm{~cm}$ defect in the left corpus cavernosum was present along with an associated peri-cavernosal hematoma beneath Buck's fascia (Fig. 2). The right corpus cavernosum and the urethra were intact. After application of a tourniquet proximal to the fracture site, the hematoma was evacuated and the tear identified (Fig. 3). Devitalized tissue was excised and the defect was repaired with 3-0 Prolene, continuous suture.

A Foley catheter was inserted which was removed on the second postoperative day. The patient received 3 days of perioperative parenteral antibiotic. He had an uneventful recovery and was discharged on the fourth postoperative day. He was advised to abstain from intercourse for two weeks. On a subsequent follow-up visit, he had satisfactory erectile and urinary functions.

\section{DISCUSSION}

The incidence of penile fractures is 1 in 175,000 pop1 ulation, which may be underreported because many patients do not seek medical attention due to embarrassment $[1,3]$. Out of the 1,642 cases reported from worldwide in 2002, $56 \%$ patients belonged to the Mediterranean region [1]. Higher prevalence in this geographic region is attributed to the cultural practice of Taqaandan, resulting in $76 \%$ of 352 penile fractures in an Iranian study [4]. It is a process of forcefully bending the top of an erect penis to achieve rapid detumescence in unsuitable situations [5]. In Europe, the injury typically occurs during vigorous

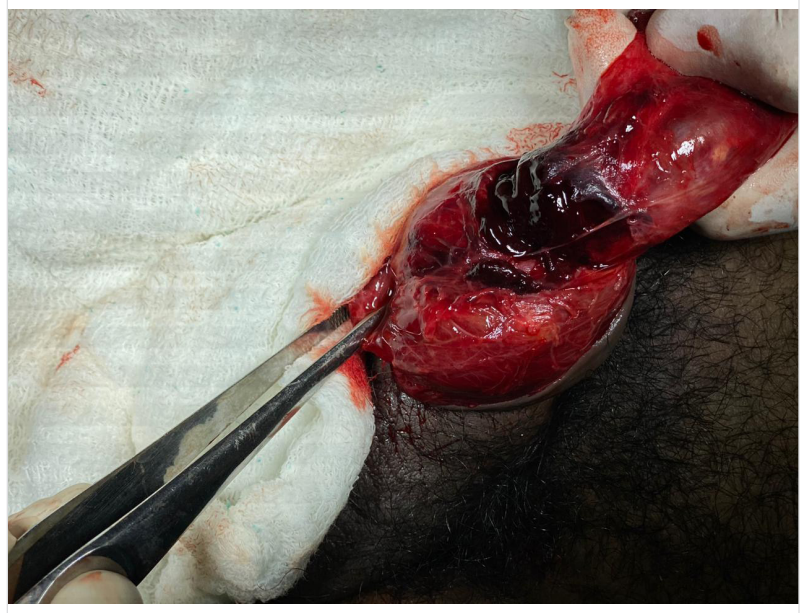

Figure 2: Penis degloved to expose fracture site showing hematoma and tear 


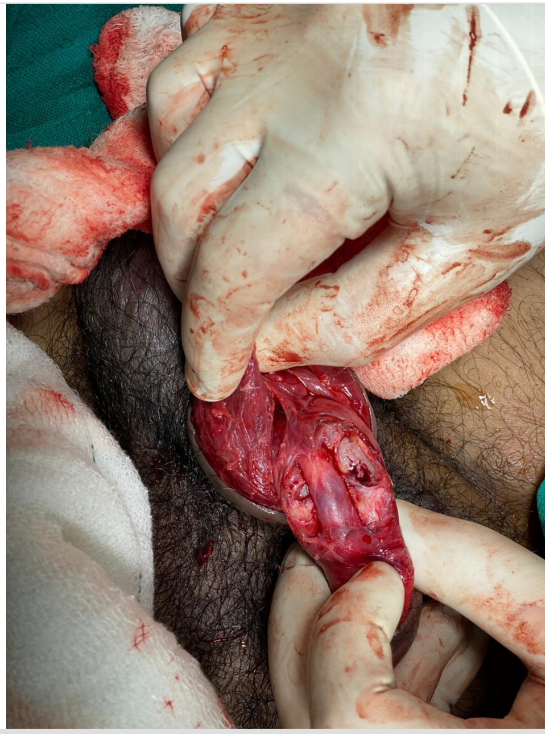

Figure 3: Exposed tear in the tunica albuginea

vaginal intercourse [1]. Other common causes of trauma include bending during masturbation and unconscious nocturnal manipulation [6].

Conservative management includes application of cold compression bandages, use of penile splints, anti-inflammatory agents, abstinence from sexual intercourse, fibrinolytic agents, and suppression of erections with antiandrogens [7]. More popular and definitive approach is immediate surgical repair, which includes complete evacuation of hematoma, identification, and closure of the tunica/ urethral injury, local corpora debridement, and ligation of any disrupted vasculature under local or spinal anesthesia as day-care surgery [8]. The success rate with immediate surgical repair is about $92 \%$, while only $59 \%$ with conservative management [9]. The latter is associated with erectile dysfunction, permanent penile curvature, damage to the urethra, pain during sexual intercourse and prolonged hospital stay in about $30 \%$ patients, while such problems occur in less than $10 \%$ of patients managed with immediate surgical repair $[7,10]$. Hence, immediate surgery within 24 hour of injury is recommended for better functional outcomes in terms of faster recovery, decreased morbidity, and lesser complications [11]. In an event of a delayed presentation like our case, surgical repair is still advocated. However, it is associated with an increased risk of long-term sequelae [11].

\section{CONCLUSION}

Denile fracture is a urological emergency. Prompt clinical diagnosis and immediate surgical repair provides a better outcome in terms of preservation of erectile and urinary functions despite a delayed presentation.
I. Eke N. Fracture of the penis. Br J Surg. 2002;89(5):555-65. DOI: 10.1046/j. I 365-2168.2002.02075.x.

2. Miller S, McAninch JW. Penile fracture and soft tissue injury. In: McAninch JW, editor. Traumatic and reconstructive urology. Philadelphia:W.B. Saunders; 1996. pp. 693-8.

3. Orvis BR, McAninch JW. Penile rupture. Urol Clin North Am. 1989; |6(2):369-75. PMID: 265286 |

4. Zargooshi J. Sexual function and tunica albuginea wound healing following penile fracture: An 18-year follow-up study of 352 patients from Kermanshah, Iran.J Sex Med. 2009;6(4): I I4I-50. DOI: I0.1 I I I/j. I743-6I09.2008.0I I I7.x.

5. Zargooshi J. Penile fracture in Kermanshah, Iran: the long-term results of surgical treatment. BJU Int. 2002;89(9):890-4. DOI: 10.1046/j. | 464-4I 0x.2002.02745.x.

6. Fergany AF, Angermeier KW, Montague DK. Review of Cleveland Clinic experience with penile fracture. Urology. 1999;54(2):352-5. DOI: 10.1016/s0090-4295(99)00II5-6.

7. Kalash SS, Young JD Jr. Fracture of penis: controversy of surgical versus conservative treatment. Urology. 1984;24(I):2I-4. DOI: 10.1016/0090-4295(84)90380-7.

8. Naraynsingh V, Maharaj D, Kuruvilla T, Ramsewak R. Simple repair of fractured penis. J R Coll Surg Edinb. 1998;43(2):97-8. PMID: 9621531.

9. Cummings JM, Parra RO, Boullier JA. Delayed repair of penile fracture. J Trauma. 1998;45(I):153-4. DOI: 10.1097/00005373$199807000-00032$.

10. Wespes E, Libert M, Simon J, Schulman CC. Fracture of the penis: conservative versus surgical treatment. Eur Urol. 1987; 13(3): 1668. DOI: I0.1 I59/000472765.

II. De Giorgi G, Luciani LG, Valotto C, Moro U, Praturlon S, Zattoni F. Early surgical repair of penile fractures: our experience. Arch Ital UrolAndrol. 2005;77(2):I03-5. PMID: |6|4627I. 